Проведен анализ адаптивного ответа клеток на различные стрессовые воздействия. 17редполагается, что клеточный адаптивный ответ независимо от природы внешнего фактора генерируется по универсальному плану и характеризуется избыточностью и неспецифичностью зацитных реакций.

Состояние адаптации может достигаться, в принципе, двумя путями: за счет непосредственного развития приспособительных реакций в ответ на действие внешнего фактора либо за счет смещения (селекции) одной популяции (клеток, организмов) другой, изначально более приспособленной к неблагоприятному фактору. Условимся под адаптивным отвстом подразумевать развитие реакций, приводящих в конечном итоге к повышению выживаемости клеток в условиях действия внешнего фактора, независимо от того, развиваются они непосредственно в ответ на действие внешнего фактора либо создают селективные преимущества одних клеток над другими.

В данной работе мы попытаемся показать, что независимо от природы стрессора адаптивный ответ клеток имеет универсальные черты и характеризуется, с одной стороны, избыточностью, с другой - неспецифичностью приспособительных реакций. Под избыточностью адаптивного ответа будем понимать развитие реакций, отсутствие которых не препятствует развитию частичной или полной устойчивости к стрессовому воздействию; под неспецифичностью приспособительных реакций - индукцию одной и той же реакции в ответ на различные неблагоприятные факторы.

В отличие от Насонова и Александрова $[1,2]$, показавших, что реакция клеток на действие раздражителей является неспецифической, рассмотрим только те реакции, адаптивное значение которых показано.

Анализ фенотипа устойчивости. Независимо от того, каким образом в клетках достигается фенотип устойчивости (см. выше), популяции устойчивых клеток проявляют ряд характерных черт. Во-первых, они гетерогенны по указанному фенотипу. Это продемонстрировано для различных стрессовых воздействий: теплового шока $[4,5]$, ионов тяжелых металлов [6], водного дефицита $[7,8]$, ряда лекарственных препаратов [10-13]. Во-вторых, часто клетки, проявляющие устойчивость к одному неблагоприятному фактору, приобретают перекрестную устойчивость к другим факторам, зачастую не сходным по физико-химической природе и мишеням действия $[14-17,20,30]$. В-третьих, фенотип перекрестной (множественной) устойчивости неоднозначен по проявлению: если для данной клеточной линии устойчивость к фактору 1 сопровождается перекрестной устойчивостью к фактору 2, то клетки, устойчивые к фактору 2 , не обязательно проявляют устойчивость к фактору 1. Так, арсенит натрия индуцирует термотолерантность фибробластов китайского хомячка, но тепловой шок не индуцирует устойчивости к арсениту [20]; линия опухолевых клеток $L 1210$, устойчивая к действию алкилирующего агепта L-PAM, проявляет перекрестную устойчивость к DDPt, но те же клетки, устойчивые к DDPt, остаются чувствительными к L-PAM [22]. Сходным образом опухолевые клетки человека, проявляющие устойчивость к алкалоидам барвинка и перекрестную устойчивость к ряду других лекарственных препаратов, остаются устойчивыми к широкому кругу этих лекарств при потере устойчивости к алкалондам барвинка [3].

Рассмотренные особенности фенотипа устойчивости наблюдаются как для модельных систем (клеток в культуре), так и для клеток организмов, обитающих в условиях постоянно действующих экстремальных факторов $[1,23,24]$. Естественно ожидать, что они являются от- 
ражением адаптивных реакций, индуцирующихся в клетках при стрессовых воздействиях.

Характеристика адаптивных ответов. Для анализа адаптивных ответов мы выбрали четыре типа стрессовых воздействий: тепловой шок, ионы тяжелых металлов, осмотический стресс и селективное давление лекарственных препаратов. На каждое из этих воздействий в клетках самых различных организмов индуцируется адаптивный ответ: синтез белков теплового шока (БТШ) при повышении температуры, металлотионеинов (MT) в присутствии тяжелых металлов, аккумуляция пролина при осмотическом стрессе и амплификация специфических генов при селективном давлении ксенобиотиков (например, дигидрофолатредуктазы (ДГФР) в присутствии метотрексата как селективного агента). В дальнейшем мы будем условно называть эти реакции адекватными. Многочисленные данные $[10,25-34]$ дают веские основания полагать, что развитие этих реакций обусловливает формированіе фенотипа устойчивости (табл. 1).

Наряду с этим существуют не менее убедительные данные, отрицающие адаптивный характер рассматриваемых ответных реакций (табл. 1).

Противоречие может быть слято, если допустить, что рассматриваемые ответные реакции являются лишь аддитивной частью (причем не обязательной) множества других приспособительных реакций, раз-

Т а бли и а 1

Адаптивное значение ответных реакций на стрессовые воздействия Adaptive value of stress-induced response reactions

\begin{tabular}{|c|c|c|}
\hline Реакция & Наличие лриспособительного значения & $\begin{array}{c}\text { Отсутствие прнспособнтельного } \\
\text { значения }\end{array}$ \\
\hline \multirow[t]{3}{*}{ Синтез БТШ } & $\begin{array}{l}\text { Кинетика синтеза БТШ совпадает с } \\
\text { кинетнкой приобретения термотоле- } \\
\text { рантности }[20,31,34]\end{array}$ & $\begin{array}{l}\text { Клеточные линии, отличающиеся } \\
\text { по термоустойчивости, синтезиру- } \\
\text { юг идентичный качественный } \\
\text { спектр БТЩ [37] }\end{array}$ \\
\hline & $\begin{array}{l}\text { Мутанты с повышенным синтезом } \\
\text { БТШ проявляют повышеную термо- } \\
\text { устойчивость }[25,36]\end{array}$ & $\begin{array}{l}\text { Фенотип термоустойчивости мо- } \\
\text { жет достигаться при полном от- } \\
\text { сутствии БТШ }[38,57,89]\end{array}$ \\
\hline & $\begin{array}{l}\text { Мутанты, дефектные по синтезу } \\
\text { БТШ, не способны развивать термо- } \\
\text { устойчивость }[28,31]\end{array}$ & $\begin{array}{l}\text { Активация синтеза БТШ «неа- } \\
\text { декватными» индукторами (изо- } \\
\text { пропилтиогалактозидом) не при- } \\
\text { водит к фенотипу термоустойчи- } \\
\text { вости [109] }\end{array}$ \\
\hline \multirow[t]{2}{*}{ Синтез МТ } & $\begin{array}{l}\text { Клетки, устойчивые к нонам } \mathrm{Cd}^{2+} \text {, } \\
\text { несут амплифицированные копии МТ- } \\
\text { генов [30] }\end{array}$ & $\begin{array}{l}\text { Сd²+-Устойчнвость может дости- } \\
\text { гаться без увеличения количества } \\
\text { МТ [6] }\end{array}$ \\
\hline & $\begin{array}{l}\text { Трансфекция МТ-генов прнводит к по- } \\
\text { вышенной устойчивости к } \mathrm{Cd}^{2+}[30]\end{array}$ & 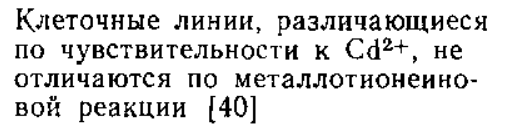 \\
\hline \multirow[t]{2}{*}{$\begin{array}{l}\text { Накопление } \\
\text { пролина }\end{array}$} & $\begin{array}{l}\text { Клеточные линии с повышенным со- } \\
\text { держанием пролина проявляют ус- } \\
\text { тойчивость к осмотическому стрессу } \\
{[16]}\end{array}$ & $\begin{array}{l}\text { Генотипы с высоким и низким } \\
\text { содержанием пролина не отлича- } \\
\text { ются по осмоустойчивости [85] }\end{array}$ \\
\hline & $\begin{array}{l}\text { Мутантные или трансформированные } \\
\text { клетки со сверхпродукцией пролина } \\
\text { проявляют повышенную устойчивость } \\
\text { к осмотическому стрессу }[33,88]\end{array}$ & $\begin{array}{l}\text { Различия в осмоустойчивости не } \\
\text { связаны с различиями в накопле- } \\
\text { нии пролина }[91]\end{array}$ \\
\hline \multirow{2}{*}{$\begin{array}{l}\text { Амплифика- } \\
\text { ция специ- } \\
\text { фических } \\
\text { генов }\end{array}$} & $\begin{array}{l}\text { Клетки, устойчивые к метотрексату, } \\
\text { несут амплифицированные колии ге- } \\
\text { на ДГФР [10] }\end{array}$ & $\begin{array}{l}\text { Қлетки, устойчивые к метотрек- } \\
\text { сату, не содержат амплифициро- } \\
\text { ванных копий ДГФР [43] }\end{array}$ \\
\hline & $\begin{array}{l}\text { Независимо полученные линии кле- } \\
\text { ток, устойчивых к метотрексату, со- } \\
\text { держат копни одного и того же } \\
\text { участка генома, коднрующего ДГФР } \\
\text { [41] }\end{array}$ & $\begin{array}{l}\text { Клетки, отличающиеся уровнем } \\
\text { устойчивости к метотрексату, } \\
\text { имеют одинаковое количество ко- } \\
\text { пий гена ДГФР [108] }\end{array}$ \\
\hline
\end{tabular}


вивающихся в клетках при действии определенного стрессового фактора.

Действительно, ряд экспериментов показал наличие других адаптивных реакций, которые могут развиваться в клетке параллельно или связанно с адекватными реакциями. Для теплового шока таковыми могут быть изменения вязкости мембран [44, 46], а также другие защитные реакции, не связанные с БТЩ [48]. Появление множества разных БТШ в ответ на тепловой шок, а также индукция их различных наборов в разных тканях одного и того же организма при неодинаковых режимах теплового стресса $[49,50]$ может указывать на то, что синтез БТШ - это комплекс защитных реакций клетки на тепловой стресс. Для тяжелых металлов защитными реакциями могут быть изменение проницаемости мембран, биохимическое обезвреживание, ускоренное выведение токсичных ионов [23], индукция неметаллотионеиновых белков [51]. Для осмотического стресса - индукция специфического набора белков [9], накопление ионов и малых органических молекул [32, 33]. В свою очередь, как өто показано на бактериях, накопление нонов, а также синтез и транспорт различных органических молекул представляют собой различные взаимодополняюшие системы защиты, которые могут работать независимо [53]. Отмечены также изменения вязкости мембран как одного из механизмов выработки устойчивости к осмотическому стрессу $[54,18]$. Для лекарственных препаратов - это уменьшение мембранной проницаемости, изменение сродства фермента-мишени к яду $[13,43,55]$, ускоренное выведение ксенобиотиков из цитоплазмы [104]. Отметим, что для всех рассматриваемых стрессов. общей реакцией являются изменения на уровне мембран.

Очевидно, «развертка» множества защитных реакций в клетках при действии определенного стрессового фактора различна, что хорошо согласуется $c$ гетерогенностью фенотипа устойчивости к неблагоприятным факторам. Иллюстрацией к этому служит работа [10], в которой показано, что популяция клеток, устойчивых к определенной концентрации метотрексата, состоит из клеток, реализующих устойчивость без амплификации гена ДГФР, и клеток с амплифицированным геном ДГФР, которые, в свою очередь, проявляют гетерогенность по числу копий гена.

Из табл. 1 следует, что ни одна из рассматриваемых адекватных реакций не является строго обязательной для реализации фенотипа устойчивости. Вероятно, это справедливо и для любой другой приспо-

Т аблиц а 2

Неспецифическал индукция защитных реакций

Nonspecilic induction of protective reactions

\begin{tabular}{c|c}
\hline $\begin{array}{c}\text { Защитная } \\
\text { реакция }\end{array}$ & Индукторы \\
\hline
\end{tabular}

Синтез Бтய Певышенная температура, холодовый стресс [111], а также более 60 других индукторов, включая тяжелые металлы, сульфгидрильные реагенты, вирусные инфекции, стероидные гормоны [34], УФ-облучение [92], сыворотку [42], аноксию [93] и осмотический стресс $[62,83]$

Синтез МТ

Ионы гяжелых металлов, тепловой шок, низкие температуры, бактериальный эндотоксин [64], глюкокортиконды [64, 65], сульфгидрильные реагенты [66], опухолевые промоторы, канцерогены, УФоблучение [30], $\alpha$-интерферон [67], сывороточные ростовые факторы и активаторы протеинкиназы С [106]

Синтез проли- Водный дефицит, повышение ионной силы окружающего раствора, на низкие температуры $[6,110]$

Амплификация Метотрексат и другие аналоги субстрата, митогенные и опухолевые специфических промоторы [70], гидроксимочевина [10], УФ-облучение, канцерогегенов (ДГФР) ны [19], гипоксия [96]

При меч ан ие. Что касается амплификации специфических генов, то перечисленные воздействия лишь усиливают амплификацию гена ДГФР, но не индуцируют ее. 
собительной реакции. Так, например, несмотря на то, что адаптивное изменение на уровне мембран при повышении температуры показано $[45,46]$, существуют примеры отсутствия коррсляции между термоустойчивостью и изменением вязкости мембран [56]. Эти данные дают основание считать, что по своему характеру адаптивные ответы клеток на стрессовые воздействия являются избыточными.

Помимо того, что приспособительные реакции не обязательны для формирования фенотипа устойчивости, они способны индуцироваться не только «адекватными» стрессовыми воздействиями, но и рядом других факторов, причем некоторые из них являются общими индукторами для различных защитных реакций (табл. 2). Из приведенной таблицы следует, что индукция БТШ возможна при всех рассмотренных нами стрессовых воздействиях, кроме селективного давления ксенобиотиков. Не исключено, что индукция БТШ происходит и в этом случае, так как некоторые агенты, способствующие амплификации специфических генов-мишеней при селективном давлении лекарственных препаратов [19], способны индуцировать БТШ (табл. 2). Кроме того, имеют. ся указания на связь БТШ с фенотипом устойчивости к лекарственным препаратам $[20,21]$.

Тем не менее представленные данные не дают оснований считать, что синтез БТШ является универсальной реакцией на стресс, поскольку в ряде работ показано, что различные стрессовые агенты индуцируют уникальные наборы белков, которые могут перекрываться или не перекрываться вовсе с БТIII $[20,62,73-75]$.

Механизмы неспецифического адаптивного ответа. Из табл. 1 и 2 следует, что адаптивные ответы клеток на различные стрессовые воздействия сходны по характеру (защитные реакции избыточны и неспецифичны). Это может приводить к перекрыванию адаптивных ответов при действии на клетку различных неблагоприятных факторов (табл. 3).

Перекрывание клеточных адаптивных ответов можно было бы объяснить активацией в клетках под действием стресса универсального плейотропного посредника (сигнала тревоги), способного воспринимать индуцирующие сигналы и запускать каскад ответных реакций. Роль таких модуляторов могли бы выполнять высокофосфорилированныс

Т а 6 ли ц а 3

Индукция зациткых реакций различными стрессовыми факторами.

Связь с перекрестной устойчивостью

Induction of protective reactions by varying stress factors. Connection with cross-resistance

\begin{tabular}{|c|c|c|c|}
\hline Стрессор & $\begin{array}{l}\text { Адекватная } \\
\text { защитная } \\
\text { реакция }\end{array}$ & $\begin{array}{c}\text { Другие } \\
\text { защитные реакции }\end{array}$ & Фснотип устойчивости \\
\hline $\begin{array}{l}\text { Повышение } \\
\text { или понижение } \\
\text { температуры }\end{array}$ & $\begin{array}{l}\text { Синтез } \\
\text { БТШ }\end{array}$ & $\begin{array}{l}\text { Синтез MT } \\
{[64]}\end{array}$ & $\begin{array}{l}\text { Термоустойчивость, холодоустойчивость } \\
\text { [11]], устойчивость к радиации * и УФ- } \\
\text { облучению [14, 80-82], устойчнвостьк } \\
\text { тяжелым металлам [77], устойчивость } \\
\text { к лекарственным препаратам [20, 21], } \\
\text { устойчивость к осмотическому стрессу * } \\
{[83,89] \text {, устойчивость к перекиси водо- }} \\
\text { рода [97] }\end{array}$ \\
\hline $\begin{array}{l}\text { Тяжелые ме- } \\
\text { таллы }\end{array}$ & Синтез МТ & $\begin{array}{l}\text { Синтез БТШ } \\
{[20,78]}\end{array}$ & $\begin{array}{l}\text { Устойчивость к металлам, термоустої- } \\
\text { чивость }[15,20 \text {, устойчивость к УФ. } \\
\text { облучению и радиации }[30,84]\end{array}$ \\
\hline $\begin{array}{l}\text { Осмотический } \\
\text { стресс }\end{array}$ & $\begin{array}{l}\text { Накопление } \\
\text { пролина }\end{array}$ & $\begin{array}{l}\text { Синтез БТШ } \\
{[83]}\end{array}$ & $\begin{array}{l}\text { Морозоустойчивость *, устойчивость к } \\
\text { засухе * [16, 110], устойчивость к по- } \\
\text { вышенным температурам * }[26,89] \text {, со-ле- } \\
\text { устойчивость }{ }^{*}[86]\end{array}$ \\
\hline Метотрексат & $\begin{array}{l}\text { Амплифика- } \\
\text { ция ДГФР }\end{array}$ & $\begin{array}{l}\text { Амплификация } \\
\text { іесцепленных } \\
\text { генов }[87]\end{array}$ & $\begin{array}{l}\text { Перекрестная устойчивость к лекарст- } \\
\text { венным препаратам [87] }\end{array}$ \\
\hline
\end{tabular}

* Обозначены случаи участия «адекватных» защитных продуктов в формировании феногипа перекрестной устойчнвости. 
динуклеотиды типа Ар4A [90], однако существуют данные, противоречащие этой гипотезе [35]. Перекрывание мишеней действия различных стрессовых факторов может служить альтернативным объяснением неспецифичсского характера адаптивного ответа. Эта модель более приемлема, поскольку отражает реальную возможность множественного повреждающего действия стрессового фактора.

Многочисленные факты, накопленные к настоящему времени, позволяют утверждать, что активация транскрипции происходит вследствие взаимодействия цис-регуляторных элементов генов с белковыми транс-активаторами [39]. Для генов БТШ и MT показано, что их 5'-регуляторные участки содержат мпожественные цис-регуляторные домены, способные независимо воспринимать различные индуцирующие сигналы.

Так, гены МТ мыши и человека содержат по меньшей мере три независимых цис-регуляторных домена, активирующихся соответственно тяжелыми мсталлами, глюкокортикоидами и другими индукторами, включающими сывороточные ростовые факторы и форболовые эфиры $[64,105]$, а БТШ70 человека содержит по крайней мере два регуляторных домена, один из которых ответствен за индукцию транскрипции тепловым шоком и тяжелыми металлами, другой - сывороточными ростовыми факторами [42]. Изложенное означает, что неспецифический характер адаптивных ответов может быть предопределен доменным типом устройства регуляторных областей соответствующих генов. Тот факт, что активация транскрипции генов осуществляется белковыми факторами (активаторами транскрипции), которые, в свою очередь, активируются при действии на клетку внешних индукторов, позволяет выделить несколько уровней, могущих приводить к перекрыванию адаптивных ответов. Следующие данные подтверждают эту точку зрения.

1. Различные индукторы (ростовые факторы и форболовый эфир ТФА) способны активировать один и тот же транскрипционный фактор [47].

2. Один и тот же индуктор (ТФА) способен активировать по меньшей мере пять разных транскрипционных факторов [52].

3. Один и тот же транскрипционный фактор (API) способен активировать транскрипцию множества генов $[58,59]$, что обусловлено, вероятно, наличием одной и той же цис-регуляторной последовательности на 5'-конце различных генов.

4. Разные транскрипционные факторы способны активировать один и тот же ген, взаимодействуя с различными цис-регуляториыми элементами $[39,47]$.

5. Не исключена ситуация, когда разные транскрипционные факторы взаимодействуют с одной и той же цис-регуляторной последовательностью $[60,61]$, а один и тот же транс-активатор связывается с разными регуляторными элементами [63].

6. Наконец, взаимодействие между транскрипционными факторами может создать дополнительные возможности для активации транскрипции различных генов $[42,68]$.

Существование сложной сети путей, приводящих к активации транскрипции генов в ответ на внешний индуцирующий фактор, может означать, что гипотеза общего плейотропного посредника (сигнала тревоги), запускающего каскад ответных реакций на стресс, равно как и множествснность мишеней действия стрессового фактора, являются слишком простыми моделями, объясняющими неспецифический характер клеточного адаптивного ответа. Кажется весьма вероятным, что вследствие доменного устройства регуляторных областей гены БТШ и MT наряду с другими клеточными генами являются составной частью индуцибельной системы (или систем), способной активироваться широким спектром различных воздействий. Не вызывает удивления поэтому, что тепловой шок индуцирует клеточный онкоген $c$-fos [69], $\gamma$-интерферон [79] и независимо от него $2^{\prime}, 5^{\prime}$-олигоаденилатсинтетазу [71]; факторы роста индуцируют термоустойчивость клеток мыши [112], а гены MT активируются такими «беспричинными» индукторами, как $\alpha$-интерферон [67], УФ-облучение [105] и йодацетат [66]. 
Функции защитных реакций. Правомерен вопрос: все ли реакции, индуцируемые определенным стрессовым воздействием, способствуют выживаемости или являются «балластными», т. е. не имеющими адаптивного значения в условиях действия этого стрессора? Тот факт, что арсенит натрия индуцирует синтез БТШ, фенотип термотолерантности, но не приводит к арсенитоустойчивости [20], свидетельствует о том, что БТШ не являются универсальными протекторами против любого стрессового воздействия, вызывающего их индукцию. С другой стороны, показана защитная роль БТШ при осмотическом стрессе [83] и ионизирующей радиации [81]. Способность белков теплового шока синтезироваться в клетках, не подверженных стрессовому воздействию [100], указывает на их функциональную роль и в нормальных условиях. Все возрастающее количество работ указывает на то, что БТШ выполняют в клетке скорее структурную, а не энзиматическую роль [72]. Не исключено, что функция их сводится к неспецифической стабилизации лабильных клеточных компонентов [98]. Тот факт, :то температурные воздействия могут приводить к перекрестной устойчивости к лекарственным препаратам $[20,21]$ и кадмиевому стрессу [77], может указывать на связь БТШ с компонентами клеточной мембраны, которая, очевидно, является первичной мишенью всех стрессовых воздействий. Подтверждает это недавно обнаруженный факт, что мембранный белок Dictyostelium discoideum, подверженный стадиеспецифиче ской регуляции, индуцируется также тепловым и холодовым шоком [76].

Представленные данные формируют впечатлеиие, что БТШ могут выполнять защитную роль при различных стрессовых воздействнях, однако они, скорее всего, не являются единственіюй системой зашиты от повреждающего действия различных стрессовых факторов, включая тепловой шок.

Подобно БТШ МТ синтезируются в нормальных условиях, индуцируются различными «неадекватными» стрессорами [30] и могут не оказывать влияния на фенотип устойчивости к тяжелым металлам [40]. С другой стороны, показано, что клетки, синтезирующие повышенное количество МТ, более устойчивы к рентгеновским лучам [84] и УФ-облучению [30].

Ввиду уникального строения МТ способны связывать значительное количество ионов металлов [51], что позволяет рассматривать их как главных регуляторов внутриклеточного метаболизма биологически важных ионов, таких, например, как цинк [105]. Это означает, что MT могут быть задействованы в важных биологических процессах, требующих металл-зависимых ферментов: репликации, репарации, транскрипции, синтеза и превращения белков [105]. Вышеизложенное предполагает, что индукция $M T$ при различных внешних воздействиях имеет, скорее всего, адаптивное значение.

Помимо специфического набора белков, индуцирующихся в ответ на осмотический стресс $[62,99]$, накопление пролина и других малых органических молекул также является частью клеточного адаптивного ответа на стрессовое воздействие [33, 102]. Хотя структурная аналогия между стрессовыми белками и пролином мала, нельзя не отметить функционального сходства. Так, подобно БТШ накопление пролина наблюдается при различных стрессовых воздействиях [32]. Экзогенный пролин, а также другие малые органические молекулы оказывают защитное действие при последующем тепловом $[27,28]$ и холодовом шоке [110]. Подобно БТШ механизм защитного действия пролина может заключаться в неспецифической стабилизации клеточных компонентов $[33,101]$. Кроме того, в силу своей структуры пролин способен выполнять ряд других функций, которые могут иметь защитное значение при осмотическом стрессе [102]. Наконец, накопление пролина при осмотическом стрессе может быть не связано с фенотипом устойчивости [85]. Это может означать, что накопление пролина, как и иядукция БТШ и МТ, является лишь частью (причем не обязательной) адаптивного ответа клеток на различные стрессовые воздействия. Фенотип множественной лекарственной устойчивости служит ил- 
люстрацией неспецифической защиты клеток на действие различных лекарственных препаратов. Накопленные $\mathrm{K}$ настоящему времени данные дают основания полагать, что он обеспечивается низкоспецифич ної системої выведения ксенобиотиков из цитоплазмы $[104,106]$. Одним из основных компонентов этой системы, очевидно, является Р-гликопротеид (gp 170) - трансмембранный белок, который гомологичен бактериальным белкам, вовлеченным в активный мембранный транспорт [106]. Амплификация гена Р-гликопротеида наблюдается в большинстве анализируемых клеточных линий, обладающих фенотипом множественной лекарственной устойчивости [107]. Хотя экспрессия Р-гликопротеида является необходимым и достаточным условием возникновения множественной лекарственной устойчивости [106], важно отметить наличие альтернативных (не связанных с Р-гликопротеидом) механизмов, обеспечивающих возникновение подобного фенотипа $[87,106]$.

Рассмотренные данные предполагают, что появление фенотипа перекрестной устойчивости при действии на клетку стрессового фактора может быть обусловлено не только индукцией разных защитных реакций, но и способностью конкретных защитных продуктов (белков или малых органических молекул) выполнять множественные или неспецифические функции.

Наличие системы индуцибельных генов, способной активироваться в ответ на действие ряда внешних индукторов, не исключает возможности того, что часть клеточного ответа на стрессовое воздействие, не принимает участия в формировании фенотипа устойчивости к нему.

Так например, трудно представить, что индукция транскрипции соріа-подобных элементов дрозофилы при тепловом шоке, происходящая, вероятно, из-за наличия цис-регуляторной последовательности, гомологичной промоторной последовательности генов БТШ [95], имеет прямое адаптивное значение, т. е. непосредственно способствует выживаемости клеток при тепловом шоке. Подобным образом БТШ, индуцируемые арсенитом натрия, не участвуют в формировании устойчивости к нему, равно как и не все гены, амплифицированные в клетках с множественной лекарственной устойчивостью, обусловливают этот фенотип $[94,107]$.

Изложенные факты формируют впечатление, что стратегия ответа клеток на стрессовые факторы заключается, с одной стороны, в индукции множества защитных реакций в ответ на конкретное стрессовое воздействие, с другой - в наделении конкретных защитных продуктов свойством неспецифического или многофункционального действия. Наличие системы индуцибельных генов, способной активироваться различными внешними воздействиями, может означать, что часть клеточного ответа на стресс не имеет адаптивного значения в условиях действия определенного стрессового фактора, т. е. индуцируется «про запас». Очевидно, что изложенная стратегия клеточного ответа на стресс от личается высокой степенью надежности. Она становится еще более значительной, если учесть, что эукариотические клетки в стрессовых условиях способны продуцировать экстраклеточный фактор (ы), индуцирующий зашитный. ответ в клетках, не подвергшихся подобному воздействию [103].

\section{ADAPTATION OF CELLS TO ENVIRONMENTAL FACTORS. CHARACTERISTIC OF} ADAPTIVE R'ESPONSES

\section{V.T. Solovyan}

Institute of Molecular Biology and Genetics,

Academy of Sciences of the Ukrainian S'SR, Kiev

Sum mar y

The cellular adaptive response to various environmental factors has been analyzed. It is supposed that adaptive response irrespective of the nature of external factor is generated according to universal plan and characterized by surplus and nonspecificity of adaptive reactions. 
1. Александров В. Я. Клетки, макромолекулы и температура.- Л.: Наука, 1975.$329 \mathrm{c.}$

2. Александров В. Я. Реактивность клеток и белка.- Л.: Наука, $1985-317$ с.

3. Reversal of vinca alkaloids resistance but not multiple drug resistance in human leukemie cells by verapamil /W. T. Beck, M. C. Cirtain, A. T. Look, R. A. Ashmun // Cancer Res.-il $986 .-46, \mathrm{~N} 2 .-\mathrm{P} .770-785$.

4. Mascarenhas J. P., Altschuler $M$. Responses to environmental heat stress in the plant embryo // Changes in eukaryotic gene expression in response to environmental stress / Eds B. G. Athinson, D. B. Walden.-Orlando: Acad. press, 1985:P. $315-326$.

5. Heterogeneity in induced heat resistance and its relation to synthesis of stress proteins in rat tumor cells clones / S. P. Tomasovic, P. L. Rosenblatt, D. A. Johnston et al. // Cancer Res.- 1984.-44, N 12.- P. 5850-5856.

6. Lieberman $M$. W., Beach L. P., Palmiter $R$. D. Ultraviolet radiation induced metallothionein-1 gene activation is associated with extensive DNA dimethylation // Cell. 1983.- 35, N 1.-P. 207-214.

7. Dasgupta J., Bewley D. J. Variation in protein synthesis in different regions of greening leaves of barley seedlings and effects of imposed water stress // J. Exp. Bot.-1984.-35, N 159.- P. 1450-1459.

8. Cellular mechanisms of tolerance to water stress / P. M. Hasegama, R. A. Bressan, S. Hand.a, A. K. Handa // Hort Science.-1984.-19, N 3.- P. 371-377.

9. Bewley J. D., Larsen R. M., Papp J. E. T. Water-stress induced changes in the patterns of protein synthesis in maize seedling mesocotyls: a comparison with the effect of heat shock // J. Exp. Bot.- 1983-34, N 146.-P. 1126-11133.

10. Brown P. C., Tlsty T. D., Schimke R. T. Enhancement of methotrexate resistance and dihydrofolate reductase gene amplification by treatment of mouse $3 \mathrm{~T} 6$ cells with hydroxyurea // Mol. and Cell. Biol.-1983.-3, N 3.-P. 1097-1107.

11. Phenotypic heterogeneity in cultured human and neck squamous cells carcinoma lines with low level methotrexate resistance/A. Rosowsky, J. E. Wrigh, C. A. Cucchi et al. // Cancer Res. - 1985.- 45, NN 12.- P. 6205-62:13.

12. Matthews P. R., Stewart P. R. Resistance heterogeneity in methicillin resistant Staphylococcus aureus // FEMS Lett. - 1984.-22, N 1.- P. 161-166.

13. Riordan $J$. R., Ling $V$. Genetic and biochemical characterization of multidrug resistance // Pharmac. Ther - 1985.-28, N 1.-P. 51-75.

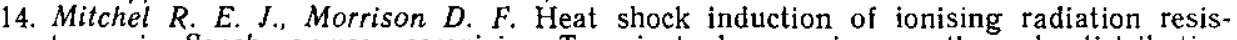
tance in Saccharomyces cerevisiae. Transient changes in growth cycle distribution and recombinational ability // Radiat. Res.-1982,-92, N 1.-P. 182-197.

15. Roberts $P . B$. Growth in cadmium-containing medium induced resistance to heat in E. coli // Int. J. Radiat. Biol.-1984.-45, N 1:-P. 27-31.

16. Van Swaai A. C. Jacubsen E., Feenstra W. J. Effect of cold hardening wilting and exogenously applied proline on leaf proline content and frost tolerance of several genotypes of Solanum //. Physiol. Plant. - 1985.-64, N 2.-P. 230-236.

17. Borst $P$. DNA amplification and multidrug resistance // Nature. - 1984. - 309, N $5969 .-$ P. 580

18. Liljenberg $C$, Kates $M$. Changes in lipid composition of oat root membranes as a function of water-deficit stress // Can. J. Biochem. Cell Biol.-1985.-63, N 1.P. $77-84$.

19. Schimke R. T. Gene amplification in cultured animal cells//Cell.- 1984.-37, N 3.- P. 705-7.13.

20. $L i$ G. C., Laszlo A. Thermotolerance in mammalian cells: a possible role for heat shock proteins // Chang eukar. gene expression in response to envirolmental stress / Eds B. G. Atkinson, D. B. Walden.-Orlando: Acad. press, 1985.- P. 227-252.

21: $L i G$. C. Heat shock proteins: role in thermotolerance, drug resistance and relationship to DNA topoisomerases // Nat. Cancer Inst. monogr.- 1987.-N 4.-P. 99103 .

22. Establishment of cross-resistance profiles for new agents / F. M. Schabel, H. E. Skipper, N. W. Trader et al. // Cancer Treat. Rep.-1983.-67, N 10- - P. 905-922.

23. Жизнь микробов в экстремальных условиях / Под ред. Д. Кашнер.- М. : Мир, $1981 .-510 \mathrm{c}$

24. Hyberg $D$., Bishop $P$. High levels of phenotypic variability of metal and temperature tolerance // Evolution.- 1983.- 37, N 2.-P. 341-357.

25. Laszlo $A$., $L i G$. C. Heat resistant variants of chinese hamster fibroblasts altered in expression of heat shock protein // Proc. Nat. Acad. Sci. USA.- 1985.-82, N 23.P. $8029-8034$

26. Hong-gi Zhang, Croos A. K., Linskens H. F. Qualitative changes in protein synthesis in germination pollen of Lilium longiflorum after a heat shock// Plant, Cell and Environ.- 1984.-7, N 9.- P. $689-691$.

27. Protection against thermal cell death in chinese hamster ovary cells by glucose or mannose / K. J. Henle, T. P. Monson, H. J. Moss, W. A. Nagle // Cancer Res.1984.-44, N 12, pt. 11.-P. 5499-5504.

28. Chaig $E$. A., Jacobsen $K$. Mutations of the heat inducible 70 kilodalton genes of yeast confer temperature sensitive growth //Cell-1984-38, N 3.- P. 84I-849.

29. Tebe $T$., Ito $K$., Yura $T$. Heat shock protein synthesis in Escherichia coli: isolation and characterization of mutants defective in heat shock induction // Ann. Rept. Inst. Virus. Res. Kyoto Univ.- 1982.-25.- P. 46-47. 
30. Karin $M$. Metallothioneins: protein in search for function // Cell. $-1985 .-41, \mathrm{~N} 1$ P. 9-10.

31. Tanguay $R$. M. Genetic regulation during heat shock and function of heat-shock protein: a review // Can. J. Biochem. Cell. Biol. - 1983.-61, N 1.-P. 387-394.

32. Greenway $H$. , Munns $R$. Mechanism of salt tolerance in nonhalophytes // Ann. Rev. Plant Physiol.-1980-31_- P. 149-190.

33. Molecular biology of osmoregulation / D. L. Rudulier, A. R. Stom, A. M. Dendokar et al. // Science.- 19184.-224, N 4653.-P. 1061-1068.

34. The heat shock response of eukaryotic cells / L. Nover, D. Hellmund, P. Noumann et al. // Biol. Zbl.- 1984.- 103, N 4.-P. 357-453.

35. Lack of correlation betwen externsive acumulation of bisnucleoside polyphosphates and the heat-shock response in eukaryotic cells /G. F. Guedon, G. J. P. Gilson, J. P. Ebel et al. // J. Biol. Chem.- 1986.-- 261, 'N 35.- P. 16459-16465.

36. Iida H., Yahara I. A heat shock-resistant mutant of Saccharomyces cerevisiae shows constitutive synthesis of two heat shock protcins and altered growth //J. Cell. Biol.- 1984.-99, N 4.-P. $1441-1450$.

37. Heat shock proteins produced by two human melanoma cell lines: absence of correlation with thermosensitivity / U. Ferrini, R. Falcioni, A. Delpino, R. Cavaliere// Int. J. Cancer- $-1984 .-34, N$ 5.P. $65.1-655$.

38. Xiao $C$.-M., Mascarenhas J. $P$. High temperature-induced thermotolerance in pollen tubes of Tradescantia and heat-shock proteins //Plant. Physiol.-i1985-78, N 4.P. $887-890$.

39. Maniatis T., Goodbourn S., Fischer J. A. Regulation of inducible and tissue-specific gene expression // Science.-1987.-236, N 4806.-P. 1237-1245.

40. Barham S. S., Enger H. D. Metallothionein response in not associated with cadmium sensitivity in some human tumor-derived cell lines //J. Cell. Biol._ 1984._-99, $\mathrm{N} 4$, pt. 2.- P. 454 .

41. MontQya-Zavala M., Hamlin $J$. L. Similar 150-kilobase DNA sequences are amplified in independently derived methotrexate-resistant Chinese hamster cells // Mol. and Cell. Biol.-1985.-5, N 4.- P. 619-627.

42. The EIA 13S product of adenovirus 5 activates transcription of the cellular human HSP70 gene / B. J. Wu, H. C. Hurst, G. C. Nicholas, R. I. Morimoto // Ibid.-1986.6. N 8.P. 2994-2999.

43. Development of methotrexate resistance in a human squamous cell carcinoma of the head and neck in culture /E. Frei, A. Rosowsky, J. E. Wright et al.//Proc. Nat. Acad. Sci. USA.- 1984.-81, N 9.-P. 2873-2877.

44. Effects of thermal adaptation at $40^{\circ} \mathrm{C}$ on membrane viscosity and the sodium-potassium pump in chinese hamster ovary cells /D. A. Bates, C. Le Grimellec, J. H. T. Bates et al. // Cancer Res.- 1985-45, N 10.- P. 4895-4899.

45. Umeki S., Marayama H., Nozama $Y$. Studies on thermal adaptation of Tetrahymena lipids alteration in fatty acid composition and its mechanism in the growth temperature shift-up // Biochim. et biophys. acta.-1983-752, N 1.- P. 30-37.

46. Cossins $A$. $R$. The adjustment of membrane fluidity during thermal adaptation // J. Therm. Biol.- 1983.-8, N 4.- P. 433-434.

47. Calcium and growth factor pathways of $c$-fos transcriptional activator require distinct upstream regulatory sequences / S. Morgan, S. T. Dougan, G. McFadden, M. E. Greenberg // Mol. Cell. Biol.-1988.8, N 7.-P. 271'7-2796.

48. Lee Y. J., Dewey W. C. Effect of cycloheximide or puromycin on induction of thermotolerance by sodium arsenite in Chinese hamster ovary cells: involvement of heat shock proteins //J. Cell. Physiol.-1987.-132, N 1.-P. 41-48.

49. Lindquist $S$. Varying patterns of protein synthesis in Drosophila during heat shock: implications for regulation // Develop. Biol. - 1980.-77, N 2.- P. 463-479.

50. Baszczynski C. L., Walden D. B.. Atkinson B. G. Maize genome response to thermal shifts // Changes in eukaryotic gene expression in response to environmental stress / Eds B. G. Atkinson, D. B. Walden-O Orlando: Acad. press, 1985_- P. 349-371.

51. Stone $H_{\text {., }}$ Overnell $J$. Non-metallothionein cadmium binding proteins // Comp. Biochem. Physiol.- 1985.-800, N 11.-P. 9-14.

52. Multiple cis- and trans acting elements mediate the transcriptional response to phorbol esters / R. Chiu, M. Imagawa, R. J. Imbra et al.// Nature.- 1987.-329, N 6140.- P. 648-651.

53. Strom A. R., Falkenberg P., Landfald B. Genetics of osmoregulation in Escherichia coli: uptake and biosynthesis of organic osmolytes //FEMS Microbiol. Rev.-1986.39.- P. $79 \longrightarrow 86$.

54. Quedraogo M., Tremolieres A., Hubas $C$. Change in fatty acids composition during water stress in cotton plants. Relation with drought resistance induced by far red light // Z. Pflanzenphysiol.- 1984.-114, N 3.-P. $239-245$.

55. Gene amplification and aitered enzymes as mechanisms for the development of drug resistance /J. R. Bertino, M. D. Carman, H. L. Woiner, A. L. A. Cashmore // Cancer Treat. Rep.-1983.-67, N 1.-P. 10

56. Konings A.W., Ruifrok A. C. C. Role of membrane lipids and membrane fluidity in thermosensitivity and thermotolerance of mammalian cells // Radiat Res. - 1985:$102, \mathrm{~N} 1 .-\mathrm{P} .86-98$.

57. Hall $B$. G. Yeast thermotolerance does not require protein synthesis //J. Bacteriol 1983.- 156, N 3.-P. 1363-1365.

58. Lee W., Mitchell $P$., Tilan $R$. Purified transcription factor AP- 1 interacts with TPAinducible enchancer elements // Cell.- 1987.-49, N 6.-P. $741-752$. 
59. Phorbol ester-inducible genes contain a common cis element recognized by a TPAmodulated trans-acting factor/P. Angel, $M$. Imagawa, R. Chiu et al.//Ibid.P. $729-739$.

60. A multiplicity of CCAATbox-binding proteins/A. Dorn, J. Bollekens, A. Staub et al. // Ibid.-50, N 6.- P. 863-872.

61. Pfeifer K., Arcangioli B., Guarente L. Yeast HAPI activator competes with the factor RC2 for binding to the upstream activation site UASI of the CYCI gene // Ibid.-49, N 1.- P. 9-18.

62. Induction of heat shock protein messenger RNA in maize mesocotyls by water stress, abscisic acid and wounding // J. J. Heikkila, J. E. T. Papp, G. A. Schultz, J. D. Bewlcy //Plant PhysioI._.1984_-76, N 1.-P. 270-274.

63. Pfeifer $K$., Prezant T., Guarente $L$. Yeast HAPI activator binds to two upstream activation sites of different sequence //Cell.- 1987.-49, N 1.- P. 19-27.

64. Induction of mouse metallothionein-1 mRNA by bacterial endotoxin is independent of melal and glucocorticoid hormones /D. M. Durnam, J. S. Hoffman, C. J. Qnaife et al. // Proc. Nat. Acad. Sci. USA.- 1984.-81, N 4.-P. 1053-1056.

65. Richards $R$. I., Hegny $A$., Karin $M$. Structural and functional analysis of the human metallothionein- $l_{a}$ gene: differential induction by metal ions and glucocorticoids // Cell.-1984.-37, N 1:- P. 263-272.

66. Durnam D. M., Palmiter $R$. D. Induction of metallothionein-1 mRNA in cultured cells by heavy metals and iodoacetate: evidence for gratuitous inducers $/ / \mathrm{Mol}$. and Cell. Biol.- 1984.-4, N 3.- P. 484-49.1.

67. Friedman R. L., Stark $G$. $\alpha$-Interferon-transcription of HLA and metallothionein genes containing homologous upstream sequences // Nature.- 1985._-314, N 6012.P. $637-639$

68. A cellular protein, activating transcription factor, activates transcription of multiple EIA-inducible adenovirus early promoters / A. W. Kevin, Tsong-Yuing Hai, Lakshmi Siva Raman et al. // Proc. Nat. Acad. Sci. USA.-1987.-84, N 23.- P. 83558359 .

69. The heat shock response in HeLa cells is accompanied by elevated expression of the c-fos proto-oncogene/K. A. Glen, M. A. Harding, I. P. Calvet, E. D. Adamson // Mol. and Cell. Biol.- 1987.-7, N 10.-P. 3452-3458.

70. Barsoum J., Varshavsky A. Mitogenic hormones and tumor promoters greatly increase the incidence of colony-forming cells bearing amplified dihydrofolate reductase genes // Proc. Nat. Acad. Sci. USA. - 1983 - 80, N 17.- P. 5330, 5334 .

71. Chousterman S., Chelbi-Alix M. K., Ming Nguy Thang. 2', '-Oligoadenylate synthetase expression is induced in response to theat shock //J. Biol. Chem.- 1987.-262, N 10.-P. $4806-48111$.

72. Piper $P$. W. How cells respond and adapt to heat stress through alterations in gene expression // Sci. Progr.- 1987.-71, N 284, pt 4.- P. 531-543.

73. Hunt L. A., Helley K.S. Nicotine-stimulated proteins in mousc cells are distinct from heat-shock proteins /./ Biochem. J.- 1984.-224, N 1.- P. 87-92.

74. Le John H. B., Braithwaite C. E. Heat and nutritional shock-induced protein of the fungus Achlya are different and under independent transcriptional control // Can. J. Biochem and Cell. Biol.- 1984.-62, N 9-P. 837-846.

75. Maytin E. V., Young $D$. A. Separate glucocorticoid, heavy metal and heat shock domains in thymic lymphocytes //J. Biol. Chem. - 1983-250, N 2? - P. $177118-17722$.

76. Maniak M., Nellen W. A developmentalty regulated membrane protein gene in Dictyostelium discoideum is induced by heat shock and cold shock//Mol. and Cell. Biol.-1988-8, N 1'- P. $153-159$.

77. Effects of temperature on cadmium toxicity to the green alga Scenedesmus acutus. Development of cadmium tolerance in batch cultures /H. J. G. ten Hoopen, P. J. Nobel, A. Schaap et al. // Antonie van Leeuwenhuck J. Microbiol.- 1985.-51, N 3.p. $344-346$.

78. Courgeon A.-M., Maisonhaute C., Best-Belpomme H. Heat-shock proteins are induced by cadmium in Drosophila cells // Exp. Cell. Res.- 1984.-153, N 2.- P. 515-521.

79. Induction of $\gamma$-interferon activity by elevated temperatures in human $\beta$-lymphoblastoid cell lines /M. W. Taylor, T. Long, M. Martiner-Valder et al. //Proc. Nat. Acad. Sci. USA.-1984,-81, N 13.-P. 4033-4036.

80. Mitchell $R$. E. J., Morison $D$. $P$. Heat shock induction of ultraviolet light resistance in Saccharomyces cerevisiae // Radiat. Res.- 1983-96, N 1.- P. 95-99.

81. Вербекко B. H. Ахмедов A. T. Kалинин B. Л. Мутанты Escherichia coli K-12 с повышенной устойчивостью к ионизирующей радиащия. Сообш. VI. Повышенная радиорезистентность и белки теплового шока //Генетика.-1986.-22, № 11.C. $2658-2663$.

82. Shimada $Y$. Heat-shock induction of radiation resistance in primordial germ cells of the fish Oryzias latipes // Int. J. Radiat. Biol-1985.-48, N 2.- P. 189-196.

83. Шерман $H$. Ю. Участие белков теплового шока в осморегуляции Escherichia coli// Молекуляр. бнология.- 1987.-21, № 1.- С. 189-193.

84. Thornalley P. J., Vasak $M$. Possible role for metallothionein in protection against radiation-induced oxidative stress, kinetics and mechanism of its reaction with superoxide and hydroxyl radicals // Biochim. et biophys, acta.-1985.-827, N 1. P. $36-45$.

85. Capacity for proline accumulation during water stress in barley and its implications for breeding for drought resistance /A. D. Hanson, C. E. Nelsen, A. R. Pedersen, E. H. Everson // Crop Sci.-1979.-19, N 5.-P. 489-493. 
86. Шевякова H. Н. Метаболизм и физиологическая роль пролина в растениях при водном и солевом стрессе // Физиология растений.-1983.-30, № 4. - С. 768-783.

87. Giulotto E., Knights C., Stark G. R. Hamster cells with increased rates of DNA amplification, a new phenotype // Cell.- 1987.-48, N 5.- P. 837-845.

88. Csonka L. N. Prohne over-production resuits in enhanced osmotolerance in Salmonella typhimurium $/ / \mathrm{Mol}$. and Gen. Genet.-1981- $182, \mathrm{~N} 1 \mathrm{-}-\mathrm{P}$. 82-86.

89. Bonham-Smith P. C., Kapoor $M$., Bewley $J . D$. Establishment of thermotolerance in maize by exposure to stress other them a heat shock does nom require heat shock protein synthesis // Plant Physiol. - 1987,-85, N 2.- P. 575-580.

90. Varshavsky $A$. Diadenosine $5^{\prime}, 5^{\prime \prime \prime}-\mathrm{p}^{\prime}, \mathrm{p}^{\prime \prime}$-tetraphosphate a pleiotropically acting alarmone // Cell. - 1983.- 34, N 3.- P. 711-712.

91. Moftah A. E., Michel B. E. The effect of sodium chloride on solute potential and proline accimulation in soybean leaves // Plant Physiol. $-1987 .-83, \mathrm{~N} 2 .-\mathrm{P} .238-$ 240.

92. Krueger J. H., Walker G. C. groEL and dnaK gene of Escherichia coli are induced by UV irradiation and nalidixic acid in an $h t p R+$-dependent fashion //Proc. Nat. Acad. Sci. USA.- 1984.-81, N 5.- P. .1499- 1503 .

93. Sciandra J. J., Subjeck J. R., Hughes $C$. S. Induction of glucose-regulated proteins during anaerobic exposure and of heat-shock proteins after reoxygenation // Ibid.N 15.- P. 4843-4847.

94. Pleiotropic drug resistance and gene amplification in a SEWA mouse tumor cell line / T. Martinsson, B. Dahllöf, Y. Wettergron et al. // Exp. Cell Res.- 1985.- 158, N 2.- P. 382-394.

95. Strand $D$. J., McDonald J. F. Copia is transcriptionally responsive to environmental stress // Nucl. Acids Res. 1985-13, N 112. - P. 4401-4410.

96. Rice G. C., Hoy C., Schimke R. T. Transient inypoxia enhances the frequency of dihydrofolate reductase gene amplification in Chinese hamster ovary cells $/ /$ Proc. Nat. Acad. Sci. USA.- 1986.-83, N 16.- P. 5978-5982.

97. Spitz D. R., Dewey W. C., Li G. C. Hydrogen peroxide or heat shock induces resis tance to hydrogen peroxide in chinese thamster fibroblasts // J. Cell Physiol.- $1987 .-$ 131, N 3.- P. $364-373$.

98. Nonspecific stabilization of stress-susceptible proteins by stress-resistant proteins: a model for biological role of heat shock proteins / K. Minton, P. Karmin, G. M. Hahl, A. P. Minton $/ /$ Proc. Nat. Acad. Sci. USA.-1982.-79, N 23.-P. 7107-7111il.

99. Ericson $M$, Alfinito $S$. $H$. Proteins produced during salt stress in Tobacco cell culture // Plant Physiol. - 1984.-74, N 3.- P. 506-509

100. Tanguay $R$. M. Intracellular localization and possible functions of heat shock proteins. Changes in eukaryotic gene expression in response to environmental stress/ Eds B. G. Atkinson, D. B. Walden.- Orlando: Acad. press, 1985.- P. 91-1113.

101. Kandpal R. P., Rao N. A. Water stress induced alteration in ornithine aminotransferase of ragi (Eleusine coracana): protections by proline against heat inactivation and denaturation by urea and guanidinium chloride $/ 1 / \mathrm{J}$. Biosci.- 1984.-6, N 1.P. $61-67$.

102. Aspinall D., Paley L. G. Proline accumulation: physiological aspects // The physiology and biochemistry of drought resistance in plant.- Sydney: Acad. press, 1981.P. $206-241$.

103. The stress response of human primary fibroblasts and its possible implications for carcinogenesis / P. Herrlich, P. Angel, H. Rahmorsdorf et al. //J. Cell Biochem.1985.- Suppl., N 9.-P. 17.

104. Нейфах A. A., Александрова A. Ю. Пониженное накопление флуоресцентных красителей в клетках, обладающих множественной лекарственной устойчивостью// Докл. АН СССР. $\rightarrow 1986 \longrightarrow 291$, № 4.- C. $989-991$.

105. Imbra R. J., Karin M. Metallothionein gene expression is regulated by serum factors arid activators of protein kinase $\mathrm{C} / / \mathrm{Mol}$. and Cell. Biol. - 1987.- 7, N 4.- P. 13581363.

106. Roninson I. B. Molecular mechanism of multidrug resistance in tumor cell $/ / \mathrm{Clin}$. Physiol. Biochem.-1987.-5, N 1.- P. 140-151.

107. Differential amplification and disproportionate expression of five genes in three multidrug-resistant chinese hamster cell lines / M. H. L. Bruiln, A. M. van der Bliek, J. L. Biedler, P. Borst $/ /$ Mol. and Cell. Biol.- 1986.-6, N 12.-P. 4717-4722.

108. Hahn P., Kapp L. N., Painter R. B. Establishment and characterization of two human cell lines with amplified dihydrofolate reductase genes $1 / /$ Exp. Cell Res.-_. 1987.168, N 1.- P. 89-94.

109. Van Bogelen R. A., Acton M. A., Neidhardt F. C. Induction of the theat shock regulon does not produce thermotolerance in Escherichia coli//Genes and Development.- 1987.-1, N 6.-P. 525-531.

110. Duncan D.R., Widholm J.M. Proline accumulation and its implication in cold tolerance of regenerable maize callus // Plant Physiol. $-1987 .-83, \mathrm{~N} 3 .-\mathrm{P}$. 703-708.

111. Heat shock protection against cold stress of Drosophila melanogaster / V. Burton H. K. Mitchell, P. Young, N. S. Petersen $/ /$ Mol. and Cell. Biol.-1988.-8, N 8.P. $3550-3552$.

112. Van Wijk Roeland, Otto A. M., De Limenez A. L. Hyperthermia can enhance the initiation of DNA synthesis stimulated by growth factors in swiss mouse $3 T 3$ cells $/ /$ Exp. Cell Res. - 1984.- 133, N 2.- P. 522-527.

Ин-т молекуляр. бнологии и генетики АН УССР, Киев

Получено 22.11 .89 